\title{
Against V-to-T-to-C movement in Japanese and Korean non-constituent coordination
}

\author{
Ryoichiro Kobayashi* $^{*}$
}

\begin{abstract}
This paper argues against syntactic verb movement in Japanese, through a case study of Non-Constituent Coordination (NCC) in Japanese and a dialectal variation of Korean. I provide novel data observing the scope relation between heads and QPs inside NCC, showing that verb movement does NOT take place. The arguments are also supported by the observations on Korean data. Moreover, I defend Fukui and Sakai’s (2003) gapping analysis of NCC, providing counterexamples to Kawazoe's (2005) arguments. This study opens a new window by providing two novel syntactic diagnostics for head movement in head-final languages. As a theoretical implication, it insists on the importance of re-examining the existence of head movement in head-final languages, for there is no overt phonological evidence for children to acquire string-vacuous movements.
\end{abstract}

Keywords. Japanese; Korean; verb-raising; head movement; coordination

1. Introduction. This study provides arguments against syntactic verb movement in Japanese, through a case study of Non-Constituent Coordination (NCC) in (1). The arguments are also supported by observations on Korean data.

a. Japanese (Koizumi 2000:228):

Mary-ga [[John-ni ringo-o huta-tu] to

Mary-NOM John-DAT apple-ACC 2-CL \&

[Bob-ni banana-o san-bon]] age-ta

Bob-DAT banana-ACC 3-CL give-PAST

'Mary gave two apples to John, and three bananas to Bob.'

b. Gyeongsang (Kyongsang) dialect of Korean:

[Taro-ka sakwa twu-kay] lang [Hanako-ka panana sey-kay] mek-ess-ta.

Taro-NOM apple 2-CL \& Hanako-NOMbanana 3-CL eat-PAST-DECL

'Taro ate two apples and Hanako ate three bananas.'

Koizumi (2000) and Funakoshi (2014) argued that in NCC such as (1), verbs head-raise to T in the Across-the-Board (ATB) fashion. In section 2, I provide counterarguments against Koizumi's verb-raising analysis, observing the scope relation between NEG and QPs inside NCC. The conclusion to be drawn is that there exists no verb-raising in NCC. Instead, I argue that NCCs in Japanese and Korean are derived via gapping in non-final conjuncts (Fukui and Sakai 2003, Kobayashi to appear, among others). Section 3 further defends the gapping analysis of NCC,

\footnotetext{
${ }^{*}$ This is a revised version of my presentation at the $90^{\text {th }}$ Annual Meeting of the Linguistic Society of America, as well as some portions of my MA thesis submitted to the Graduate School of Languages and Linguistics, Sophia University. I would like to especially thank Naoki Fukui, Takaomi Kato, and Toru Ishii. I also wish to thank Saetbyol Seo, Dorothy Ahn, the two anonymous reviewers of the LSA $90^{\text {th }}$, the organizers and the audience there. All remaining errors and inadequacies are of course mine. The author is supported by Grant-in-Aid for JSPS Fellows $16 J 00637$.

Author: Ryoichiro Kobayashi, Sophia University \& Japan Society for the Promotion of Science (JSPS)

(ryoichiro.k@eagle.sophia.ac.jp).
} 
referring to apparent counterarguments from Kawazoe (2005). Section 4 is the overall summary of the paper.

\section{Coordinate structure and De Morgan's Laws.}

2.1. NON-CONSTITUTE COORDINATION IN JAPANESE. It has been observed that the scope between subject numerals and NEG is ambiguous (Hayashishita and Ueyama 2012 and others) in Japanese. ${ }^{1}$ In (2), both the $3>\neg / \neg>3$ readings are possible.

(2) San-nin-no josi-ga ringo-o tabe-nakat-ta

3-CL-GEN girl-NOM apple-ACC eat-NEG-PAST

'Three girls didn't eat an apple.'

a. $3>\neg$ : There are 3 girls who didn’t eat an apple.

b. $\neg>3$ : It is not the case that 3 girls ate an apple.

If a verb raises in NCC (3), it moves to NEG, T, and to C in the ATB-fashion, creating [V-NEGT-C], as in (4). It predicts that NEG in C unambiguously takes a wide scope over the whole NCC. However, the NCC in (30) only allows the Num $>\neg / \neg>$ Num readings, but NOT the $\neg>$ NCC reading $(\neg(\mathrm{p} \wedge \mathrm{q})=\neg \mathrm{p} \vee \neg \mathrm{q})$. If the $\neg>$ NCC reading were available, then $p \wedge \neg q$ or $\neg p \wedge q$ should be allowed, but this is never the case.

$$
\begin{aligned}
& \text { [San-nin-no josi-ga ringo-o kinoo] to } \\
& \text { 3-CL-GEN girl-NOM apple-ACC yesterday \& } \\
& \text { [huta-ri-no dansi-ga banana-o kyoo] tabe-nakat-ta }
\end{aligned}
$$

2-CL-GEN boy-NOM banana-ACC today eat-NEG-PAST

a. Num > ᄀ: [There are 3 girls who didn’t eat an apple today] $\wedge$ [there are 2 boys who didn't eat a banana yesterday].

b. $\neg>$ Num $(\neg p \wedge \neg q)$ : [It's not the case that [ 3 girls ate an apple today]] $\wedge$ [It's not the case that $[q 2$ boys ate a banana yesterday]].

c. $*_{\neg}>\boldsymbol{N C C}(\neg(p \wedge q)=\neg p \vee \neg q)$ : It is not the case that [[ 3 girls ate an apple] $\wedge[q 2$ boys ate a banana]].

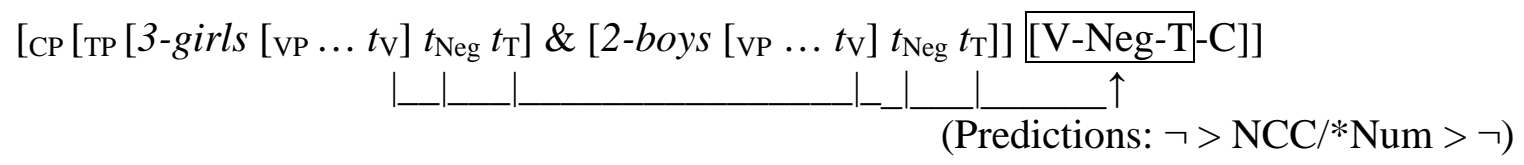

If the reconstruction were optional here, either Num $>\neg$ or $\neg>$ Num would be obtained, say the complex head that raised interpreted in the intermediate head. However, the empirical observation above shows that it is not the case. From these discussions, I argue that the relevant reconstruction effects, if verb raising occurs at all, are obligatory, but not optional. Since head movement lacks reconstruction effects under the general assumption (Lasnik 1998, Boeckx 2000), and it is empirically impossible to distinguish obligatory reconstructions in the covert component from a mere PF-movement that does nothing to do with semantic interpretations, I argue that proponents of the verb-raising analysis must bear a burden of proof that the relevant

\footnotetext{
${ }^{1}$ Han et al. (2007) claims that scope-changing head movement takes place in SOV languages. She conducted experiments and investigated whether the head movement of V/NEG expands its scope in Korean. One thing I would like to note here concerning the work of Han et al. is that in Japanese, whether the subject QP unambiguously takes a wide scope over NEG is still controversial, contra Miyagawa (2001). I believe that further investigation is necessary to conclude that her conclusion applies to Japanese data.
} 
obligatory reconstruction occurs in the convert component. In other words, as long as we do not have such evidence, it is safe to conclude that the verbs do not undergo movement in Narrow Syntax.

Before proceeding to the next section, some remarks on the distinction between total and partial reconstruction are in order. Sauerland and Elbourne (2002) convincingly showed that total reconstruction in general should be regarded as a mere PF-movement; that is, there is no movement in Narrow Syntax or the following reconstruction either. If verbs undergo total reconstruction, then the verb-raising analysis reaches a dead end, since they make wrong predictions on the scopal relations that we have observed in this chapter. ${ }^{2}$ To sum up, I have shown that Japanese NCCs do not involve any verb raising in Narrow Syntax, but instead, adjacent verb heads undergo morphological merger to satisfy the agglutinative nature of this languages, along with Sauerland and Elbourne's (2002) claim that total reconstruction is actually a PF-movement.

2.2. NON-CONSTITUENT COORDINATION IN GYEONGSANG KOREAN. This chapter provides further supports for the gapping analysis of NCC from Gyeongsang dialect of Korean. This dialectal variation is spoken in the southeastern province of Korea, and allows NCC with a nominal coordinator just as Japanese does, as illustrated in (5).

$$
\begin{aligned}
& \text { NCC in Gyeongsang Korean (Saetbyol Seo p.c.) (=1): } \\
& \text { [Taro-ka sakwa twu-kay] lang [Hanakho-ka panana sey-kay] mek-ess-ta. } \\
& \text { Taro-NOM apple 2-CL \& Hanako-NOM banana 3-CL eat-PAST-DECL } \\
& \text { 'Taro (ate) two apples and Hanako ate three bananas.' }
\end{aligned}
$$

Although in the Seoul Standard dialect, NCC is not acceptable at all (Dorothy Ahn p.c.), Gyeongsang dialect allows NCC with a nominal coordinator lang in (5). ${ }^{3}$ Moreover, judgment may vary even among the speakers of Gyeongsang dialect. Nevertheless, those who accepted NCC in Gyeongsang Korean all agreed that they yielded parallel results concerning the scope

\footnotetext{
${ }^{2}$ However, there seems to be one point that needs to be mentioned: Takaomi Kato (p.c.) noted to me that there is a possibility that the relevant reconstruction is partial, but not total. That is, features of semantic (scopal) interpretations are obligatorily reconstructed, while the other features (i.e. $\varphi$-features and subcategorizational features, and possibly others) are interpreted in the landing site. If this is correct, then the observations in this chapter do not obtain conclusive counterevidence against the verb-raising analysis.

Let us take up and assess some of such features each by each. First, as for the $\varphi$-features, I assume that they are absent in Japanese (Fukui 1986/1995 among others), or defective at the best if it exists at all. Next, concerning the subcategorial features, I briefly cover up Chomsky's (1995) and Adger's (2003) arguments. Chomsky states that checked features remain in the checked position. Since subcategorizational requirements, say of a verb, must be satisfied in its base position, it is plausible to argue that they are interpreted in the original position. On the other hand, Adger (2003) claims that subcategorizational features are deleted and become invisible for further operations once they are in the checking relation with arguments (Adger 2003:67-68). As for these features, it is not unnatural to claim that they do not undergo partial reconstruction.

It is true that still other features may exist and they might be interpreted in the landing site of a syntactically raised verb in Japanese. Thus, discussions here are not compelling enough to conclude that the relevant reconstruction, if it exists, is not partial but total. However, to the best of my knowledge, there is no such evidence for the relevant reconstruction to be partial but never total. More importantly, since there exists no overt effect of such partial reconstruction at either interface, I argue that the relevant reconstruction should be analyzed as total reconstruction. Therefore, I argue that it is safe to conclude that verbs undergo PF-movement or post-syntactic merger with adjacent heads to its right.

${ }^{3}$ In this connection, Jeong Hyeon Kim (p.c.) noted to me that Gyeongsang dialect allows a lot of short answers that involve ellipsis, which might be related to the reason why NCC is allowed in Gyeongsang dialect, whereas it is not in the Seoul Standard Korean. It needs further investigations, but I will leave the final verdict to future research.
} 
with the Japanese data we have observed above. I claim that observations in this section are of great importance to the discussions on whether verbs raise in strictly head-final languages.

Now we are ready to observe Korean NCCs. In (6), both $3>\neg / \neg>3$ readings are possible, just as in the Japanese counterpart in section 2.1.

(6) Sey-myeng-uy sonyeo-ka sakwa-lul mek-ci anh-ass-ta

3-CL-GEN girl-NOM apple-ACC eat-CI NEG-PAST-DECL

'Three girls didn't eat an apple.'

a. $3>\neg$ : There are 3 girls who didn't eat an apple.

b. $\neg>3$ : It is not the case that 3 girls ate an apple.

If verbs raise in (6) below, it moves to NEG, T, and C in the ATB-fashion, creating [V-NEG-T$\mathrm{C}]$. Therefore, just as the similar example in Japanese in section 2.3, it predicts that NEG in C unambiguously takes a wide scope over the whole NCC, as in (7). However, it only allows the Num $>\neg / \neg>$ Num readings, but never the $\neg>N C C$ reading.

$$
\begin{array}{lll}
\text { [Sey-myeng-uy } & \text { sonyeo-ka sakwa] lang } \\
\text { 3-CL-GEN } & \text { girl-NOM apple \& } \\
\text { [twu-myeng-uy } & \text { sonyen-i panana] mek-ci anh-ass-ta } \\
\text { 2-CL-GEN } & \text { boy-NOM banana eat-CI Neg-PAST-DECL }
\end{array}
$$

a. Num $>\neg$ : [There are 3 girls who didn’t eat an apple] $\wedge$ [there are 2 boys who didn’t eat a banana].

b. $\neg>\operatorname{Num}(\neg p \wedge \neg q)$ : [It's not the case that $[p 3$ girls ate an apple]] $\wedge$ [It's not the case that $[q 2$ boys ate a banana]].

c. $*_{\neg}>N C C(\neg(p \wedge q)=\neg p \vee \neg q)$ : It is not the case that [[ ${ }_{p} 3$ girls ate an apple] $\wedge[q 2$ boys ate a banana]].

Overall, the observations on two types of Korean NCCs in this section pose problems on the string-vacuous verb raising analysis.

To sum up, I have shown in this section that syntactic verb raising does not occur in Japanese or Korean NCC. If a verb head raised in Narrow Syntax, then it would be semantically detectable, unless they totally and obligatorily reconstruct back in the covert component. In the next chapter, I propose an alternative account that is based on Fukui and Sakai's (2003) gapping analysis. The analysis is developed in the framework of DM, which I believe, better captures the agglutinative nature of the verbal complex in Japanese and possibly in other strictly head-final languages.

2.3. INTERIM CONCLUSION. Let us reexamine the data we observed above under gapping approach. The schematic representation of (3) and (7) is in (8) (irrelevant details are omitted). It is rather straightforward to conclude that the gapping approach correctly predicts the scope between heads and QPs, and heads and NCC, since there is no syntactic movement of verb heads.

$$
\begin{aligned}
& \text { [ср [3-girls [vp .... } \\
& \text { (Predictions: } \neg>\text { Num/Num }>\neg / *_{\neg}>N C C \text { ) }
\end{aligned}
$$

We have seen in this section that the gapping approach can, but the verb-raising (Koizumi 2000) analysis cannot fully explain the nature of NCC. ${ }^{4}$ I do not discuss exactly how the gapping in

\footnotetext{
${ }^{4}$ Funakoshi (2014) and Kobayashi (to appear) further demonstrated some deficits of Takano's (2002) oblique movement approach.
} 
non-final conjuncts derives NCC in this paper due to the space-limitation. Readers are led to Fukui and Sakai (2003), and also to Kobayashi (2016), which attempted to eliminate a somewhat obscure post-syntactic operation, namely PF-reanalysis proposed by Fukui and Sakai.

In the next section, I take up several residual issues that the post-syntactic analysis of NCC must work on. Kawazoe (2005) provided several counterexamples against the gapping analysis. In what follows, I present empirical evidence against these objections in defense of the postsyntactic analysis of NCC.

\section{Counterarguments against Kawazoe (2005).}

In this section, we review some counterarguments from Kawazoe (2005) against the gapping analysis, and offer solutions to each of them.

3.1. OTAGAI IN NON-CONSTITUENT COORDINATION. Let us start with her first counterexample in (9) below. She claims that otagai-no sensei 'each other's teacher' is interpreted in a way described in (10).

(9) Kawazoe 2005:51(55):

a. Taro-ga dansigakusei hito-ri to Ziro-ga josigakusei hito-ri-o Taro-NOM male:student 1-CL \& Ziro-NOM female:student 1-CL-ACC otagai-no sensei-ni syookaisi-ta. each:other-GEN teacher-to introduce-PAST 'Taro (introduced) one male student, and Ziro introduced one female student to each other's teacher.'

b. Taro-ga Hanako(-ni ik-kai) to Ziro-ga Mary-ni (ik-kai)

Taro-NOM H.-to 1-time \& Ziro-NOM M.-to 1-time

otagai-no sensei-o syookaisi-ta.

each:other-GEN teacher-ACC introduce-PAST

Lit. 'Taro (introduced) to Hanako (once), and Ziro introduced to Mary (once) each other's teacher.'

(10) Kawazoe 2005:51-52(56):

a. Taro introduced one male student to Ziro's teacher, and Ziro introduced one female student to Taro's teacher. (=9a)

b. Taro introduced Ziro's teacher to Hanako once, and Ziro introduced Taro’s teacher to Mary once. $(=(9 b))$

If the NCCs above are derived from sentences in (10) via gapping, she argues that it is not clear why interpretations in (9) are possible, given that sentences (11) in each conjunct do not obtain the intended readings in (9), as illustrated in (12).

(11) Adapted from Kawazoe (2005:52(57),(58)):

a. [[vP1 Taro-ga dansigakusei hito-ri-o otagai-no_sensei-ni-syookaisi] $\varnothing$

Tato-NOM male:student 1-CL-ACC each:other-GEN teacher-to introduce \&

[VP2 Ziro-ga josigakusei hito-ri-o otagai-no sensei-ni syookaisi]-ta]

Ziro-NOM female:student 1-CL-ACC each:other-GEN teacher-to introduce-PAST

b. [[vp1 Taro-ga Hanako-ni ik-kai өtagai-no sensei-o syookaisi] $\varnothing$

Taro-NOM Hanako-to 1-time each:other-GEN teacher-ACC introduce \&

[vp2 Ziro-ga Mary-ni ik-kai otagai-no sensei-o syookaisi]-ta]

Ziro-NOM M.-to 1-time each:other-GEN teacher-ACC introduce-PAST 
(12) Judgment unchanged from Kawazoe (2005:52(59)):

(10a) VP1: *Taro-ga dansigakusei hito-ri-o otagai-no sensei-ni syookaisi-ta

Taro-NOM male:student 1-CL-ACC each:other-GEN teacher-to introduce-PAST

'Taro introduced one male student to each other's teacher.'

VP2: *Ziro-ga josigakusei hito-ri-o otagai-no sensei-ni syookaisi-ta

Ziro-NOM female:student 1-CL-ACC each:other-GEN teacher-to introduce-PAST

'Ziro introduced one female student to each other's teacher.'

(10b) VP1: *Taro-ga Hanako-ni ik-kai otagai-no sensei-o syookaisi-ta

Taro-NOM Hanako-to 1CL each:other-GEN teacher-ACC introduce-PAST

'Taro introduced each other's teacher to Hanako once.'

VP2: *Ziro-ga Mary-ni ik-kai otagai-no sensei-o syookaisi-ta

Ziro-NOM Mary-to 1CL each:other-GEN teacher-ACC introduce-PAST

'Ziro introduced each other's teacher to Mary once.'

Given these observations, Kawazoe concludes that the gapping analysis fails, for there must be otagai in each conjunct. I argue, however, that her counterargument does not suffice to discard the gapping analysis or the post-syntactic analysis of NCC.

It has been convincingly shown that otagai is not a local reciprocal anaphor that must be subject to the Binding Condition A (Hoji 2006); hence its syntactic and semantic behaviors are quite different from those of each other in English. Hoji argues that otagai has a structure that has pro as its specifier in (13a), which makes it possible for this lexical item to have an anaphoric interpretation via co-indexation in a way explained in (13b).

Hoji (2006:1):

a. The internal structure of otagai is [NP pro [N otagai]].

b. What has been considered as the anaphoric relation between otagai and "its antecedent" must be understood as that between the pro in [NP pro [N otagai]] and the antecedent of pro.

Predictions of the proposal (13) are indeed borne out, as exemplified in (14) through (16). The example in (14) illustrates that otagai need not have its antecedent in its local domain; (15) shows that there is no c-command requirement for otagai and its antecedent, unlike the true reciprocal anaphors such as each other; and (16) exemplifies that the split antecedence is possible between otagai and its antecedents, which cannot be explained if otagai were a local anaphor that is constrained by the Binding Condition A. The examples in (14) through (16) are all from Hoji (2006:3).

(14) [John to Bill $]_{i}$-wa [cP Mary-ga [pro ${ }_{i}$ [otagai]]-ni horetei-ru to] omoikondei-ta. John \& Bill-Top Mary-NOM each:other-DAT be:in:love THAT believe-PAST

a. '[Each of John and Bill] believed that Mary was in love with the other.'

b. '[Each of John and Bill $]_{i}$ believed that Mary was in love with himi.'

(15) $\quad\left[\mathrm{pro}_{i}[\right.$ otagai $]$-no koibito $]$-ga [John to Bill $]_{i}$-ni iiyot-ta each:other-GEN lover-NOM John \& Bill-DAT try:to:seduce-PAST

'John's lover tried to seduce Bill, and Bill's lover tried to seduce John.'

(16) Ieyasu ${ }_{i}$-wa Nobunagaj-ni [Singen-ga sin-eba

Ieyasu-TOP Nobunaga-DAT Singen-NOM die-COND

[pro $_{i+j}$ [otagai]]-no ryoodo-ga sibaraku-wa antai-da to] tuge-ta. 
each:other-GEN territory-NOM for:a:while-TOP safe-COP THAT tell-PAST

'Ieyasu told Nobunaga $_{j}$ that, if Shingen dies, their ${ }_{i+j}$ territories will be safe for a while.'

Given these observations, there is no empirical reason to prevent otagai from having the same indices with its antecedents that do not c-command it, or are not in the local domain with it. Needless to say, the antecedents do not have to be a single constituent, given that otagai allows split-antecedence in (16). Therefore, I assume that otagai in each conjunct can take both Taro and Ziro as its split antecedents, which do not c-command it, as illustrated in (17) and (18). ${ }^{5}$

\footnotetext{
${ }^{5}$ In this connection, some notes on another counterexample of Kawazoe are in order. The NCC in (i) is originally gave a banana to are compared. Therefore, in (i), the meaning of the sentence provides a context for comparison, unlike (ii). Takano calls this reading Sentence Internal Reading (SIR), following Carlson (1987).

(i) John-ga ringo-o hito-tu to Bill-ga banana-o ip-pon John-NOM apple-ACC 1-CL \& Bill-NOM bananaACC 1-CL onaji/tigau hito-ni kat-ta same/different person-to buy-PAST

'John (bought) an apple and Bill bought a banana for the same/different person.'

(ii) John-ga onaji/tigau ringo-o kat-ta John-NOM same/different apple-ACC buy-PAST 'John bought the same apple/different apples.'
} from Takano (2002): He argues that (i) has a reading in which the individuals whom John gave an apple to and Bob

(Takano 2002:274(86))

(Sentence External Reading)

Kawazoe claims that the gapping analysis predicts that (i) is derived in a way exemplified in (iii) below. Note that SIR would be unavailable if (i) were derived through gapping, since each conjunct then may contain onaji/tigau 'same/different.' It is obvious that sentences in (iva) and (ivb) cannot be interpreted as SIR.

(iii) [John-ga ringo-o hito-tu-onaji/tigau hito-ni kat-ta] to John-NOM apple-ACC 1-CL same/different person-to buy-PAST \& [Bill-ga banana-o ip-pon onaji/tigau hito-ni kat-ta] B.-Nom banana-Acc 1-Cl same/different person-to buy-Past

(iv) a. *John-ga ringo-o hito-tu onaji/tigau hito-ni kat-ta (as SIR) John-NOM apple-ACC 1-CL same/different person-to buy-PAST 'John bought an apple to the same/different person.'

b. *Bill-ga banana-o ip-pon onaji/tigau hito-ni kat-ta Bill-NOM banana-ACC 1-CL same/different person-to buy-PAST 'Bill bought an apple to the same/different person.'

(adapted from Kawazoe 2005:56)

This is however, not necessarily the case. Hoji (1998:134) notes that betubetu 'different,' which induces SIR, can have a structure that is parallel with otagai as in (v).

(v) [pro [betubetu]

(cf. [x-betubetu]: adapted from Hoji 1998:134 footnote 7) Given that lexical items like onaji/tigau also cause SIR in a similar manner as betubetu, it is not unnatural to assume that they have the same structure as betubetu in (v). Then, the same argument from otagai applies to Kawazoe's counterexample in (i): onaji/tigau in the first conjunct is elided under the semantic/phonological identity. The derivation is illustrated in (vi).

(vi) a. Narrow Syntax:

$$
\begin{aligned}
& \text { [[VP1 } \mathrm{John}_{i[\mathrm{Nom}]} \text { ringo }_{[\mathrm{Acc}]} \text { hito-tu onaji/tigau }{ }_{i+j} \text { hito }_{[\text {Dat }]} \text { age] Ø } \\
& \text { John apple 1-CL same/different person give \& } \\
& \text { [vP2 } \text { Bill }_{j[\text { Nom] }} \text { banana }_{[\text {Acc] }} \text { ip-pon onaji/tigau }{ }_{i+j} \quad \text { hito }_{\text {[Dat] }} \text { age]-ta] } \\
& \text { Bill banana 1-CL same/different person give-PAST }
\end{aligned}
$$


a. Narrow Syntax: (=10a)

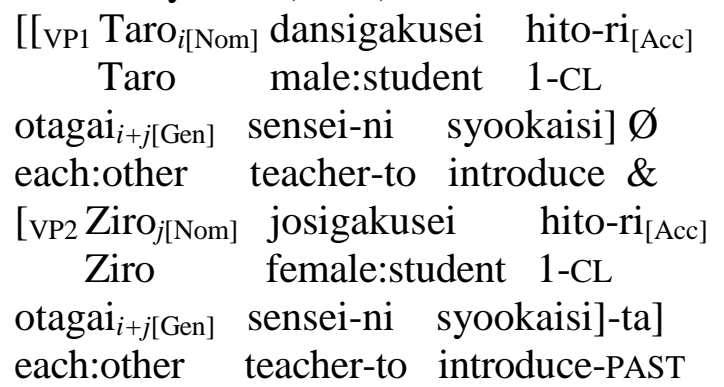

b. Post-Syntactic Component (Gapping + to-insertion to \&):

[[Taro ${ }_{i}$-ga dansigakusei hito-ri otagat $_{i+j}$-no-sensei-ni syookaisi] to

[Ziro ${ }_{j}$-ga josigakusei hito-ri-o otagai ${ }_{i+j}$-no sensei-ni syookaisi]-ta]

c. Derived Sentence:

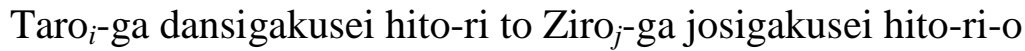
otagai $_{i+j}$-no sensei-ni syookaisi-ta

a. Narrow Syntax: (=10b)

\begin{tabular}{|c|c|c|}
\hline$\left[{ }_{\mathrm{VP} 1} \operatorname{Taro}_{i[\mathrm{Nom}}\right]$ & ] Hanako-ni & ik-kai \\
\hline Taro & Hanako-to & 1-time \\
\hline $\mathrm{ai}_{i+j}$-no & sensei $[$ Acc] & syookaisi] \& \\
\hline & & \\
\hline $\begin{array}{c}\operatorname{lvP2}^{Z_{1}} \text { Ziro }_{j[\mathrm{Nom}]} \\
\text { Ziro }\end{array}$ & Mary-nı & k-kai \\
\hline Ziro & Mary-to 1 & -time \\
\hline each:other te & teacher i & introduce-PAST \\
\hline
\end{tabular}

b. Post-Syntactic Component (Gapping + to-insertion to \&):

[[Taro ${ }_{i}$-ga Hanako-ni ik-kai otaga $_{i+j}$-no-sensei-o-syookaisi] to

[Ziro $_{j}$-ga Mary-ni ik-kai otagai ${ }_{i+j}$-no sensei-o syookaisi]-ta]

c. Derived Sentence:

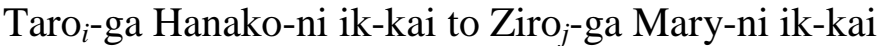

otagai $_{i+j}$-no sensei-o syookaisi-ta

Some may claim that the sentence before phonological deletion should also have the same interpretation as the derived sentence (Takaomi Kato p.c.). Indeed, it seems quite difficult to obtain the same interpretation as (17c) and (18c) in (17a) and (18a), in which otagai in each conjunct is overtly pronounced and takes split antecedence, namely Taro and Ziro. I argue that it is the ellipsis of otagai that licenses the reading in (17c) and (18c) through vehicle change in the spirit of Fiengo and May (1994). The sentence in (19a) is ungrammatical due to the Binding

b. Post-Syntactic Component (Gapping + to insertion):

[[John ${ }_{i}$-ga ringo-o hito-tu enaji/tigau ${ }_{i+j}$ - hito-ni-age] to

John-NOM apple-ACC 1-CL same/different person-to give \&

[Bill -ga banana-o ip-pon onaji/tigau $_{i+j}$ hito-ni age]-ta]

Bill-NOM banana-ACC 1-CL same/different person-to give-PAST

c. Derived Sentence:

John $_{i}$-ga ringo-o hito-tu to Bill $_{j}$-ga banana-o ip-pon onaji/tigau ${ }_{i+j}$ hito-ni age-ta John-NOM apple-ACC 1-CL \& Bill-NOM banana-ACC 1-CL same/different person-to give-PAST 'John (bought) an apple and Bill bought a banana for the same/different person.' 
Condition $\mathrm{C}$ violation. However, the ellipsis under identity makes the relevant sentence grammatical, as in (19b). They claim that phonological ellipsis allows vehicle change to occur: In (19c), John in the ellipsis site is, according to Fiengo and May, interpreted as him instead.

Adapted from Fiengo and May (1994:220-221):

a. *Mary [loves $\mathrm{John}_{i}$ ] and he ${ }_{i}$ thinks Sally does [love $\mathrm{John}_{i}$ ] too.

b. Ellipsis:

*Mary [loves $\mathrm{John}_{i}$ ] $_{\text {and }}$ he thinks Sally does [love John ${ }_{i}$ \} too.

c. Vehicle change:

${ }^{\mathrm{OK}}$ Mary [loves $\mathrm{John}_{i}$ ] and he $\mathrm{i}_{i}$ thinks Sally does [love him $\mathrm{H}_{i}$ too.

Only after the phonological deletion can the offending R-expression in (19b) can undergo vehicle change into a suitable guise. The insight behind this operation vehicle change is that phonological ellipsis may have some repair effects regarding the binding/co-indexing mechanisms. ${ }^{6}$ Given these observations, I assume that a similar repair strategy is at work in (17) and (18), which supports the alternative analysis to Kawazoe's counterexample.

3.2. SUSPENDED AFFIXATION AND NON-CONSTITUENT COORDINATION. Another counterargument is in (20), in which NCC involves a complex predicate V-au 'V to one another.' Note that in (20), at least two different events must be involved: Prof. Yamada introduced one male student to Prof. Tanaka, and Prof. Tanaka introduced one female student to Prof. Yamada.

Kawazoe (2005:55(69)):

[Yamada-sensei-ga dansigakusei hito-ri] to [Tanaka-sensei-ga

Yamada-prof-NOM male:student 1-CL \& Tanaka-prof-NOM

josigakusei hito-ri]-o syookaisi-at-ta.

female:student 1-CL-ACC introduce-do:one:another-PAST

'Prof. Yamada introduced one male student to Prof. Tanaka, and Prof. Tanaka introduced one female student to Prof. Yamada.'

A verbal suffix -au 'do:one:another' is attached to syookais- 'introduce,' obtaining the reading where each professor introduces his student to one another in (19). If it is derived through gapping, then the structures before deletion would be [Yamada-sensei-ga dansigakusei hito-ri-o syookaisi-at-ta] and [Tanaka-sensei-ga josigakusei hito-ri-o syookaisi-at-ta], which do not have an interpretation in (20). Therefore, Kawazoe concludes that the gapping analysis fails to explain data such as (20).

Recently, however, a considerable amount of research on verbal suffixes in Japanese has been done in the framework of DM. Verbal suffixes in Japanese are often suspended on the nonfinal verbs in coordination. They are called Suspended Affixation (Kornfilt 2012, Nishiyama 2016 among others). Typically, in VP-coordination in Japanese, only the second verb gets the morphological realization of tense suffix (Takano 2004). Whether the suspended affix is interpreted on the non-final verbs depends on each type of affixes. In the case of -au, it requires at least two individuals/events for the representation to be interpretable. Thus, it is natural to assume that -au is affixed to the whole coordinate structure, as in (21).

$$
\begin{aligned}
& {\left[_ { \mathrm { TP } } \left[{ } _ { v \mathrm { P } } \left[\left[_{v \mathrm{P}} \text { Yamada-sensei }_{[\mathrm{Nom}]} \text { dansigakusei-hito-ri }{ }_{[\text {Acc }]} \text { syookaisi }\right] \varnothing\right.\right.\right.} \\
& \text { Yamada-prof male:student-1CL introduce \& }
\end{aligned}
$$

\footnotetext{
${ }^{6}$ There has been a numerous number of studies on other repair effects, island repair for instance. See Nakao (2009) and the references cited therein for more details.
} 
[vP Tanaka-sensei TNom] $_{\text {josigakusei-hito-ri }}$ [Acc]
Tanaka-prof female:student-1CL introduce-AU-PAST

Given the structure is interpreted phase-by-phase, it is plausible to argue that each conjunct is transferred by its $v$ phase head, and then after that, the suspended affix - $a u$ is attached to the whole spelled-out coordinated $v \mathrm{P}$. The rough semantic formulation of [[- $a u]]$ is schematically illustrated in (22). ${ }^{7}$ I assume that - $a u$ is a one-place function that takes one coordinated structure denoting plural events with an unvalued variable in each conjunct, as illustrated in (22a). This function returns two events each with a value taken from another conjunct respectively as in (22b). The sentence in (20) is interpreted in a way that prof. Tanaka in the second conjunct is interpreted as an indirect object in the first conjunct, and prof. Yamada in the first conjunct is interpreted as an indirect object in the second conjunct. I assume that the variables in (22a) correspond to the indirect objects, and $x$ in the first conjunct receives its value from the constant $\beta$ in the second conjunct, while $y$ in the second conjunct receives its value from the constant $\alpha$ in the first conjunct.

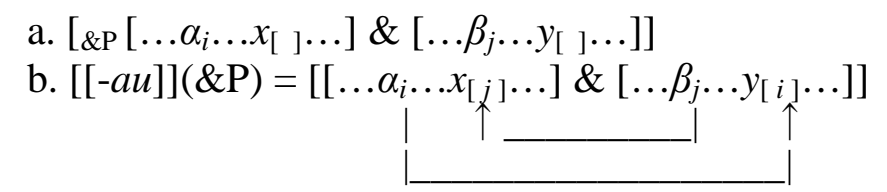

After the structure is transferred to the post-syntactic component, the gapping occurs in the first conjunct, hence obtaining the surface string in (20), as illustrated in (23). Note that the accusative case marker in the first conjunct is phonologically suppressed, due to the morphophonological filter that prohibits the sequence of a case particle and to (see Koizumi 2000 and Kobayashi 2016).
[TP [ ${ }_{\nu \mathrm{P}}\left[\right.$ [ ${ }_{\mathrm{P}}$ Yamada-sensei-ga dansigakusei-hito-ri syookaisi] to Yamada-prof-NOM male:student-1CL introduce \&
[vP Tanaka-sensei-ga josigakusei-hito-ri-o syookaisi]]-at]-ta].
Tanaka-prof-NOM female:student-1CL-ACC introduce-AU-PAST
'Prof. Yamada introduced one male student to Prof. Tanaka, and Prof. Tanaka introduced one female student to Prof. Yamada.'

To sum up, I have shown that the post-syntactic analysis correctly explains the data in (20). Again, it is not plausible to argue that the gapping analysis fails from data like (20).

3.3. RESPECTIVE READINGS AND NON-CONSTITUENT COORDINATION. Next, we turn to Kawazoe's (2005) final counterexample, in which two NCCs are involved. Each conjunct in the first NCC obtains respective readings with those in the second NCC, as in (24). The schematic representation is in (25a), which obtains a respective reading described in (25b).

(24) Kawazoe (2005:54(65)):

A-kaijoo-de daigakusei-ga huta-ri to

room:A-at univ:student-NOM 2-CL \&

B-kaijoo-de koukousei-ga hito-ri

room:B-at high:school:kid-NOM 1-CL

\footnotetext{
${ }^{7}$ I thank Gen Fujita (p.c.) for pointing this out to me. I do not go into the details on how semantics of -au work in deriving the relevant reading (20) in this paper. As for the more detailed discussions on the semantics of events and plurality, see Schein (1993) and the series of his works.
} 
syutoo-de kawara-o nijuu-mai to keri-de ita-o juu-mai wat-ta. chop-by clay:tile-ACC 20-CL \& kick-with board-ACC 10-CL break-PAST

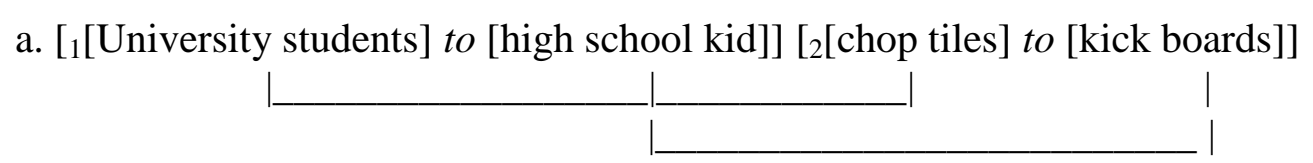

b. 'Two university students (cracked) 20 clay tiles with their chop at Room A, and one high school kid cracked 10 boards with his/her kick at Room B.'

Kawazoe claims that the gapping analysis may derive the surface strings of (24) but it fails to obtain the relevant respective reading. The underlying structure of (24) under the gapping analysis will be something like (26). Since [[syutoo-de kawara-o nijuu-mai wat(-ta)] \& [keri-de ita-o juu-mai wat(-ta)]] 'cracked 20 clay tiles with chop and 10 boards with kick' must appear in each conjunct, it is impossible to gain the relevant respective reading in (24b), though it may obtain the group reading, which I will explain.

(26) Kawazoe (2005:54(68)):

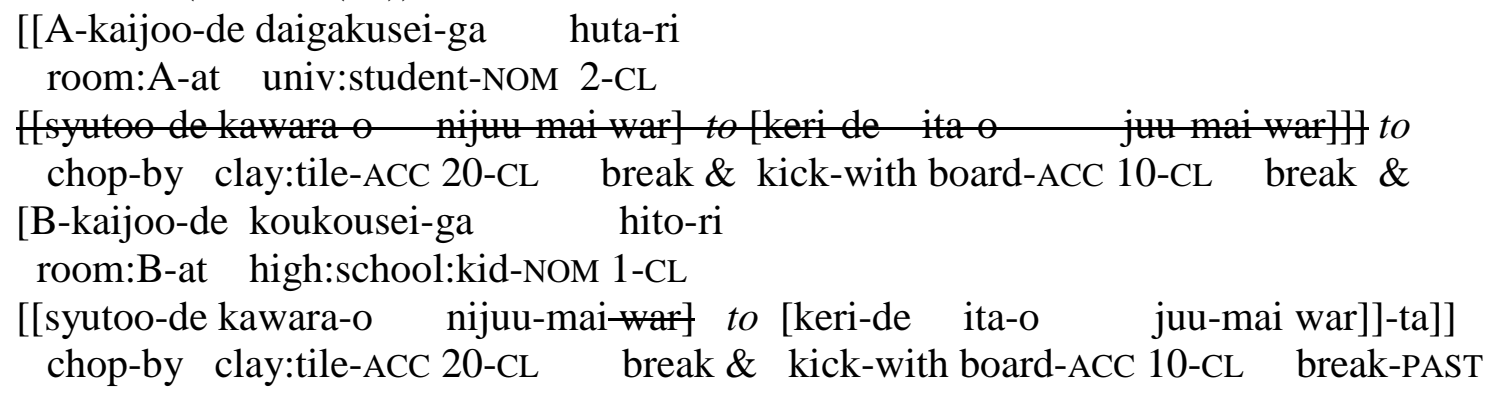

The availability of respective readings has long been used as counterevidence against the gapping analysis of Right-Node-Raising (Abels 2004 and others). However, it has also been doubted recently whether the respective reading is syntactic in nature or not (Gawron and Kehler 2004 and the series of their works). The dependency among conjuncts in (23a) is a cross-serial dependency, which can be non-syntactic (see Fukui 2014 for more details). Indeed, a respective reading might be available for some speakers, but the grammatical judgments on this reading are subtle and vary considerably from individual to individual (Gawron and Kehler 2004). ${ }^{8}$ Needless to say, it is the group reading in (27) that speakers obtain without any inconsistency in judgment.

\footnotetext{
${ }^{8}$ Even if we assume that the relevant respective reading is obtained syntactically, I argue that the post-syntactic analysis might derive the relevant respective reading in (24). Suppose that the sentence in (24) has an underlying structure in (i), in which the first and the second NCCs contain pros in the object positions and the subject positions respectively. After combining (ia) and (ib) via adjunction or coordination, the gapping of the verbal elements occurs post-syntactically, as illustrated in (ii) below.

$\begin{array}{ccc}\text { (i) a. [[CP A-kaijoo-de daigakusei-ga } & \left.\text { huta-ri }{ }_{k} \text { pro }_{i} \text { war-ta }\right] & \varnothing \\ \text { room:A-at univ:student-NOM } & 2-\mathrm{CL} & \text { break-PAST \& }\end{array}$

[CP B-kaijoo-de koukousei-ga hito-ri pro $_{j}$ war-ta]] room:B-at high:school:kid-NOM 1-CL break-PAST

'Two university students broke pro $_{i}$ in the room A, and one high school kid broke pro $_{j}$ in the room B.'

b. [[CP pro $_{k}$ syutoo-de kawara-o nijuu-mai ${ }_{i}$ war-ta $] \quad \varnothing$ chop-by clay:tile-ACC 20-CL break-PAST \&

[СР pro $_{l}$ keri-de ita-o juu-mai ${ }_{j}$ war-ta]]

kick-with board-ACC 10-CL break-PAST

' pro $_{k}$ broke 20 clay tiles with his/her chop, and prol broke 10 boards with his/her kick.'
} 
a. Non cross-serial dependency [1 [University students \& high school kid]]...[2 [chop tiles \& kick boards]]

b. [Two university students at Room A and one high school kid at Room B] cracked [20 clay tiles with their chop and 10 boards with their kick].

c. It was cracking [20 clay tiles with their chop and 10 board with their kick] that [two university students at Room A and one high school kid at Room B] did.

Given an amount of research in favor of semantic/pragmatic account on the respective reading, those who argue that this is derived syntactically must bear a burden of proof and explain sources of the vast discrepancy among speakers' judgment. As long as the gapping analysis is able to derive (24) as illustrated in (26), Kawazoe's example is insufficient to maintain her counterarguments against the gapping analysis of NCC.

3.4. INTERIM CONCLUSION. To recapitulate, I conclude that these three different pieces of counterevidence from Kawazoe are not compelling enough to discard the post-syntactic analysis of NCC. In this section, I have reexamined several possible counterarguments against the postsyntactic analysis of NCC. Given the discussions above, none of these arguments succeeded in discarding the post-syntactic approach. In concert with the proposal in the previous section, the arguments in this section lend further credence to the claim that verb heads do not move in Narrow Syntax, but undergo merger in the post-syntactic component.

\section{Conclusion.}

To sum up, I have argued that there is no V-to-T-to-C movement in Japanese or Korean NCC, both of which are strictly head-final languages. The present study opens a new window by providing a novel syntactic diagnostic for head movement in head-final languages. The present study covers up only a portion of string vacuous (head) movement in strictly head-final languages; hence at this point, we are still agnostic about the whole picture. Needless to say, further inquiry is needed to conclude that there is no string-vacuous (head) movement in Japanese or in the human languages in general. However, I hope that this paper contributes to sounding a note of warning against any linguistic research in defiance of the poverty-of-stimulus argument. That

(ii) [cp [[A-kaijoo-de daigakusei-ga huta-ri pro $_{i}$-war-ta] \& room:A-at univ:student-NOM 2-CL break-PAST

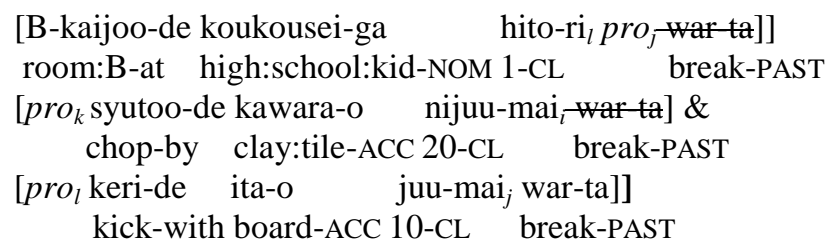

The existence of pros makes the relevant respective reading possible through coindexation. In (ia), pros are in object position; hence I assume that they are interpreted as zero topics in the CP layer. This is compatible with the fact that a word like sorezore 'respectively' makes the respective interpretation more prominent, given that coindexation is not strictly constrained syntactically. In the first place, it is doubtful whether a respective reading is obtained syntactically. Even so, the post-syntactic analysis proposed in the section 3 can still derive the sentence in (24) as illustrated above. Therefore, it is implausible to discard the post-syntactic analysis of NCC only from the data such as (24). 
is, it insists on the importance of re-examining the existence of head movement in head-final languages, for there is no overt phonological evidence for children to acquire string-vacuous movements

\section{References}

Abels, Klaus. 2004. Right node raising: ellipsis or across the board movement? Proceedings of the North Eastern Linguistic Society 34, 45-59.

Adger, David. 2003. Core syntax: A minimalist approach. Oxford: Oxford University Press.

Boeckx, Cedric. 2000. An additional note on pseudogapping. In Kerstin Schwabe, \& Ning Zhang (eds.). Ellipsis in conjunction, 117-132. Tübungen: Max Niemeyer Verlag.

Bošović, Željko, \& Steven Franks. 2000. Across-the-board movement and LF. Syntax, 3(2), $107-$ 128. http://dx.doi.org/10.1111/1467-9612.00027

Carlson, Greg. 1987. Same and different: some consequences for syntax and semantics. Linguistics and Philosophy, 10(4), 531-565. http://dx.doi.org/10.1007/BF00628069

Chomsky, Noam. 1995. The minimalist program. Cambridge, MA: MIT press.

Fiengo, Robert., and Robert May. 1994. Indices and identity. Cambridge, MA: MIT press.

Fukui, Naoki. 1986. A theory of category projection and its applications. Cambridge, MA: MIT dissertation. Revised version published as Fukui, Naoki. 1995. Theory of projection in syntax. Stanford, CA: CSLI Publications, and Tokyo: Kurosio Publisher.

Fukui, Naoki. 2014. A note on weak vs. strong generation in human language. In Ángel Gallego, \& Ott Dennis (eds.). 50 years later reflections on Chomsky’s aspects, 125-132. Cambridge, MA: MIT Press.

Fukui, Naoki, \& Hiromu Sakai. 2003. The visibility guideline for functional categories: Verb Raising in Japanese and related issues. Lingua, 113(4), 321-375.

http://dx.doi.org/10.1016/S0024-3841(02)00080-3

Funakoshi, Kenshi. 2014. Syntactic head movement and its consequences. The University of Maryland: College Park. UMD dissertation.

Gawron, Mark., \& Andrew, Kehler. 2004. The semantics of respective readings, conjunction, and filler-gap dependencies. Linguistics and Philosophy, 27(2), 169-207.

http://dx.doi.org/10.1023/B:LING.0000016452.63443.3d

Han, Chung-Hye., Lidz, Jeffrey., \& Julien Musolino. 2007. V-raising and grammar competition in Korean: Evidence from negation and quantifier scope. Linguistic Inquiry, 38(1), 1-47. http://dx.doi.org/10.1162/ling.2007.38.1.1

Hayashishita, Jun'ichi R., \& Ayumi Ueyama. 2012. Quantity expressions in Japanese. In Edward Keenan, and Denis Paperno (eds.). Handbook of Quantifiers in Natural Language, 535-612. Netherlands: Springer.

Hoji, Hajime. 1998. Null object and sloppy identity in Japanese. Linguistic Inquiry, 29(1), 127152. http://dx.doi.org/10.1162/002438998553680

Hoji, Hajime. 2006. Otagai. In Ayumi Ueyama (ed.). Theoretical and empirical studies of reference and anaphora - Toward the establishment of generative grammar as an empirical science. A report of the Japan Society for the Promotion of Science Grant-in-Aid for Scientific Research (B), Project No. 15320052, 126-138. Kyushu University.

Kawazoe, Ai. 2005. Dooshi/koo-meishiku-no imigoosei-to bunkoozoo. [Semantic Composition and Sentence Structure of Verb/Argument Noun Phrases]. Kyushu University: Kyushu University dissertation. 
Kobayashi, Ryoichiro. 2016. Eliminating PF-reanalysis. English Linguistics, 33(1). http://doi.org/10.9793/elsj.33.1_100

Kobayashi, Ryoichiro. to appear. Against V-to-T-to-C movement in Japanese: A Case Study of Non-Constituent Coordination. In Proceedings of the $11^{\text {th }}$ Workshop on Altaic Formal Linguistics. (Downloadable at http://ling.auf.net/lingbuzz/002705)

Koizumi, Masatoshi. 2000. String vacuous overt verb raising. Journal of East Asian Linguistics 9, 227-285. http://dx.doi.org/10.1023/A:1008311420647

Kornfilt, Jaklin. 2012. Revisiting "suspended affixation" and other coordinate mysteries. In Laura Brugè (ed.). Functional heads: The cartography of syntactic structures, 181-196. Oxford: Oxford University Press.

Lasnik, Howard. 1998. Some reconstruction riddles. In Proceedings of the 22nd Penn Linguistics Colloquium. 83-98.

Miyagawa, Shigeru. 2001. The EPP, scrambling, and wh-in-situ. In Michael Kenstowicz (ed.). Ken Hale: A Life in Language, 293-338. Cambridge, MA: MIT Press.

Nakao, Chizuru. 2009. Island repair and non-repair by PF strategies. The University of Maryland: College Park. UMD dissertation.

Nishiyama, Kunio. 2016. Verbal coordination in Japanese from the perspective of suspended affixation. Ms. (Under review for Glossa, special issue on suspended affixation).

Sauerland, Uli, and Paul Elbourne. 2002. Total reconstruction, PF movement, and derivational order. Linguistic Inquiry, 33(2), 283-319. http://dx.doi.org/10.1162/002438902317406722

Schein, Barry. 1993. Plurals and events. Cambridge, MA: MIT Press.

Takano, Yuji. 2002. Surprising constituents. Journal of East Asian Linguistics, 11(3), 243-301. http://dx.doi.org/10.1023/A:1016011311546

Takano, Yuji. 2004. Coordination of verbs and two types of verbal inflection. Linguistic Inquiry, 35(1), 168-178. http://dx.doi.org/10.1162/ling.2004.35.1.168 